\title{
Mathematical Modelling for Patient Selection in Proton Therapy
}

DOI:

10.1016/j.clon.2018.01.007

\section{Document Version}

Accepted author manuscript

Link to publication record in Manchester Research Explorer

\section{Citation for published version (APA):}

Mee, T., Kirkby, N., \& Kirkby, K. (2018). Mathematical Modelling for Patient Selection in Proton Therapy. Clinical Oncology, 30(5), 299-306. https://doi.org/10.1016/j.clon.2018.01.007

\section{Published in:}

Clinical Oncology

\section{Citing this paper}

Please note that where the full-text provided on Manchester Research Explorer is the Author Accepted Manuscript or Proof version this may differ from the final Published version. If citing, it is advised that you check and use the publisher's definitive version.

\section{General rights}

Copyright and moral rights for the publications made accessible in the Research Explorer are retained by the authors and/or other copyright owners and it is a condition of accessing publications that users recognise and abide by the legal requirements associated with these rights.

\section{Takedown policy}

If you believe that this document breaches copyright please refer to the University of Manchester's Takedown Procedures [http://man.ac.uk/04Y6Bo] or contact uml.scholarlycommunications@manchester.ac.uk providing relevant details, so we can investigate your claim.

\section{OPEN ACCESS}




\title{
Mathematical Modelling for Patient Selection in Proton Therapy
}

\author{
T.Mee ${ }^{1,2,3}$, N.F.Kirkby ${ }^{1,2,3}$ \& K.J.Kirkby ${ }^{1,2,3}$ \\ 1. Division of Cancer Sciences, School of Medical Sciences, Faculty of Biology, Medicine and Health, University of \\ Manchester, United Kingdom. \\ 2. The Christie NHS Foundation Trust, Manchester, United Kingdom. \\ 3. NIHR Manchester Biomedical Research Centre, Manchester University, Manchester Academic Health Science Centre, UK.
}

Corresponding Author: Dr Thomas Mee, University of Manchester, Wolfson Molecular Imaging Centre, 27 Palatine Road, Manchester, M20 3LJ.

Email address: Thomas.Mee@Manchester.ac.uk

\section{Statement of Search Strategies Used}

We searched PubMed and Google Scholar in 2017 for relevant literature on patient selection, normal tissue complication probability modelling, quality-adjusted life-years, markov modelling, cost-benefit modelling and demand modelling for proton therapy.

\section{Abstract}

Proton beam therapy (PBT) is still relatively new in cancer treatment and the clinical evidence base is relatively sparse. Mathematical modelling offers assistance when selecting patients for PBT and predicting the demand for service. Discrete event simulation, normal tissue complication probability, quality-adjusted life years and Markov Chain models are all mathematical and statistical modelling techniques currently employed but none is dominant. As new evidence and outcome data become available from PBT, comprehensive models will emerge that are less dependent on the specific technologies of radiotherapy planning and delivery.

\section{Keywords}

Mathematical Modelling, Proton Therapy, Discrete Event Simulation, NTCP, Patient Selection 


\section{Introduction}

In this paper, the mathematical modelling tools for patient selection and demand prediction for Xray radiotherapy (RT), in general, and proton beam therapy (PBT), in particular, are presented and compared. The modelling frameworks vary considerably in their scale of scrutiny, from bottom-up descriptions of DNA damage at the molecular level, to patient population, or top-down, and statistical models. The latter depend heavily on the quality and granularity of the data and predictions available for populations (size, age and location), disease incidence and treatment effectiveness as well as the occurrence and severity of side effects. Patient selection is inevitably linked to cost and benefit and the evidence base for the cost of PBT is now developing rapidly, given the number of centres operating and the total number of patients treated. There are still significant gaps and uncertainties in this evidence base, including for rare tumours and the effects of retreatment, which will have to be spanned by mathematical and statistical modelling for the foreseeable future and, to paraphrase Box, "all models are wrong, but some may be useful" [1].

\section{Cost of PBT}

While the exact cost of building and operating a proton therapy facility will always be case dependent, the overall cost of new facilities often attracts political and press attention, although it should be noted that the cost of RT compares favourably with the cost of other cancer treatments. In the UK, the total cost of radiotherapy, including PBT, accounts for less than $10 \%$ of the cancer budget [2]. The Department of Health is paying $f 250 \mathrm{~m}$ for two, 4 room, centres [3] and centres in the USA have reported capital costs of between $\$ 150 \mathrm{~m}[4]$ and $\$ 200 \mathrm{~m}[5]$. In contrast, the capital cost of a new linear accelerator and associated buildings is approximately $f 2.5 \mathrm{~m}[6]$ and the cost of a combined magnetic resonance and X-ray radiation therapy machine (MR Linac), for example the Elekta Unity machine, is in excess of $£ 5 \mathrm{~m}[7]$.

When comparing costs, it has to be remembered that a proton therapy facility typically has three to five gantries or treatment lines. More recently, smaller cyclotrons and compact gantries have 
allowed cheaper, single treatment room facilities to be developed. Since 2010, 11 of the 38 centres that have opened and 16 of the 40 under construction have a single treatment room. The capital cost of a single treatment room facility is reported to be about $\$ 40 \mathrm{~m}$ [8]. In addition, to the initial capital costs, the operating costs of a proton facility, including the treatment delivery costs, are also higher, estimated at around 2.4 [9] - 2.5 [10] times that of conventional X-ray therapy. However, with technology improvements and wider adoption this figure is expected to drop.

The high costs of PBT facilities means there is a greater requirement to ensure that the treatment capacity is filled efficiently to ensure value for money. While the cost effectiveness of proton therapy has been reported more recently [11], one of the first publications appeared in 2005 [10]. However, with the increasing popularity of proton therapy, and changes in the technology and operating procedures, older studies may no longer be relevant. The introduction of new X-ray technologies (e.g. MR Linac) and new treatment regimens (such as hypo-fractionation) could also affect the validity of the older comparisons.

Proton therapy facilities have also provided little evidence of cost-effectiveness [12] and clinicaleffectiveness [13], with the latter an important component when calculating the former. Without direct clinical evidence for improved treatment, it can be difficult to justify the large expenditure on PBT compared to other radiotherapy modalities.

\section{Demand Modelling}

Mathematical and statistical modelling for both patient selection and the demand for services is not new in radiotherapy (RT) service planning. Some of the currently published comprehensive demand models originate from CCORE in Australia [14], Canada [15] and Malthus in England [16, 17] and are solved by discrete event simulations (DES). Discrete event models (DEM) are starting to be used for health simulations $[18,19]$. In Malthus, for instance, discrete events include sampling population and cancer incidence data to construct virtual patients with statistically representative age, sex, 
home location and disease at presentation. Then each virtual patient is presented to an evidencebased decision tree aligned with the RCR fractionation guidelines [20]. Each virtual patient accumulates a virtual patient record of arbitrary complexity but typically including the type and number of fractions of radiotherapy received. At the end of a simulation, the virtual patient records are analysed statistically, partly to check that enough patients have been simulated to ensure reproducible results. Finally the whole process can be embedded in a Monte Carlo simulation to calculate the effects of the uncertainties in the parameters of the model from the population, incidence and clinical decision making events. The output is the probability densities for the number of fractions delivered, broken down by the type of RT, location, age, sex and disease type etc. To illustrate the decision tree structure, Figure 1 shows a section from the Malthus lung cancer clinicaldecision tree.

These models, described above, are currently used to predict service demand without reference to service availability. They require comprehensive data to populate the clinical decision trees, linked with granular population and incidence data or projections to capture demand variations within a country over time [21]. Once such a model has been established and validated, it is not computationally expensive to modify parameters, re-run simulations and compare outputs, so that these models can be used to estimate the impact of introducing a new technology into an established health-care system, especially where specific target clinical indications are to be compared [22]. A DEM can be used to estimate the corresponding reduction in demand for existing services. These models can also be used to predict the likely patient availability for clinical trials [22], however it is not always possible to predict accurately the success rate in actual patient recruitment. Similarly, like many other modelling technologies, DEM struggles for precision when the event rate is low as is inevitably the case for rare cancers in small geographical regions.

The current level of available clinical evidence will not allow for prediction of demand for PBT that is directly comparable to the prediction of conventional radiotherapy demand. 


\section{Cost-Benefit Modelling}

With evidence for specific indications, a cost-utility analysis can be carried out including the calculation of quality-adjusted life-years (QALY) [23]. A QALY takes into account a number of outcomes and side effects to describe a health state, or utility, with a score of 0-1 where 0 indicates death and 1 indicates perfect health. 1 QALY is representative of a single year lived in perfect health [24]. To calculate the overall QALY value of a specific intervention, the numbers of years spent, in each of several health states, are combined. The cost of the specific intervention is then used to calculate the cost per QALY gained. With PBT, the QALYs gained are often compared to X-ray therapy to check if PBT is cost-efficient. For the UK, the National Institute for Health and Care Excellent (NICE) set a value of $£ 20,000$ or less per QALY gained to be considered cost-effective [25, 26].

Temporal discounting is normally applied to QALY calculations when calculating the benefit in the future $[23,27]$. Discounting is used to account for the fact that the major costs are incurred at treatment prescription but the health benefits occur later [28].

A systematic review by Amin et al [29] provides an overview of QALYs being used for cost-effective comparisons of prostate cancer treatment. QALYs are often used in conjunction with Markov Chains to compare different treatment options for a single disease site. Markov Chains are used to model a system with changing states such as 'diseased', 'treated', 'cured' etc. As a simulation proceeds in time, the different states can carry a health-utility score and the scores are combined, as mentioned above, to give the overall QALYs for each specific treatment pathway. A QALYs analysis for PBT in England has been conducted by the NHS as will be discussed further below.

\section{Modelling Patient Selection}

For both the overseas proton therapy programme of the UK National Health Service (NHS), and the service proposed for Manchester and London, patient selection criteria are based on a defined 
clinical indication list [30,31]. Since the NHS is publicly funded and free at the point of use, it cannot spend $f 250 \mathrm{~m}$ on a technology without prior evidence of its effectiveness. These criteria enable the service to be offered to those patients where there is a clear, definable benefit for proton therapy at a cost-effectiveness level that agrees with NICE's QALY guidelines. The Department of Health's National Proton Beam Therapy Service Development Programme used a QALY/Markov Chain method for the proposed case-mix to demonstrate cost effectiveness [30, 31]. It was estimated that introducing proton therapy for 1,500 patients per year would generate 48,000 additional QALYs, with a discounted benefit over conventional radiotherapy of $f 1 \mathrm{bn}$. This equates to approximately f20.8k per QALY gained. For comparison, a study on low-risk prostate cancer calculated the cost per QALY gained for proton therapy over conventional radiotherapy at $\$ 169,867$ [32].

In a resource limited service, but where there are no regulations to define which patients should receive proton therapy, then a patient prioritisation method could be used to select patients. The patients given the highest priority should be the same as in an indication regulated service (such as the NHS), but the list will then extend to at least some other indications with decreasing priority. In some cases, tumours would be ranked, and treated, with an 'expected benefit' where there is absence of data on the actual outcomes. The Roberts Proton Therapy Center at the University of Pennsylvania adopted the prioritisation method, developing the Proton Priority System (PROPS) and reported on it after three years of treatment [33]. Unfortunately, during the study period of PROPS, the capacity exceeded the demand for service and so no firm conclusions can be made about this method yet.

PBT can be used to dose escalate the tumour at fixed risk of normal tissue complication, or, if the probability of local control is acceptable, the risk of normal tissue complication can be reduced. Both strategies assume that the dose-response for protons is broadly similar to, or can be scaled from, the X-ray response, e.g. via the concept of relative biological effectiveness (RBE) [34, 35] . However, there is a slowly gathering body of scientific and clinical evidence that fixed, constant 
values of RBE may need to be replaced by plans which allow the dose to be biologically optimised to the tumour and its microenvironment [36] .

The scientific evidence comes from an improving understanding of how DNA damage profile varies with linear energy transfer (LET), how LET varies with position within a Bragg peak and hence within a PBT treatment plan. The clinical evidence suggests a range of toxicities, usually associated with the distal edge of the Bragg peak in some relatively rare circumstances.

\section{Normal Tissue Complication Probability (NTCP) Modelling}

The Netherlands has published their proposed methodology for patient selection $[37,38]$. They will use a dual track approach: one track is a relatively non-controversial fixed indication list based on evidence at levels 1 and 2, but a second track, using a " $\triangle N T C P$ " approach will be run in parallel. The first track is not expected to exceed the capacity under installation in the Netherlands, so they anticipate some spare capacity to be available for their second track.

The $\triangle$ NTCP approach that has been proposed will work as follows: any patient can be referred to this track if they have a tumour that is not on the fixed indication list. At the PBT centre, optimised X-ray and proton plans will be produced. These plans will then be assessed for normal tissue complication probability (NTCP) and if the NTCP of most concern for the X-ray plan exceeds the equivalent NTCP for the proton plan by more than some nationally agreed difference ( $\triangle N T C P)$ then the patient will be treated with protons. As time passes, the threshold $\triangle$ NTCP can be adjusted by a feedback mechanism so that supply and demand become broadly matched. If the $\triangle$ NTCP threshold increases over time, to manage demand, further capacity can be considered. Furthermore, it is proposed that patients who just fail to meet the $\triangle$ NTCP criteria may be eligible for an appropriate randomised clinical trial where capacity permits.

The $\triangle$ NTCP approach requires considerable infrastructure to develop the NTCP models of sufficient statistical quality and sophisticated technologies are being employed (see, for example [39-42]). The 
intended major advantage of this system is to provide an efficient and transparent mechanism for both patients and clinicians to be able to understand and justify the chosen treatment pathway. However, the matched X-ray and PBT plans will have to be produced and compared quickly so as not to compromise clinical effectiveness.

The $\triangle$ NTCP method for selecting patients is potentially vulnerable to the general problem of the effect of observation delay time on feedback systems [43]. Some normal tissue complications may only become evident some years after treatment, especially in paediatric cases. Observation of these complications will be recorded and fed back into the NTCP models. At which point the corrected NTCP model may no longer indicate that PBT is the preferred modality. The large delay times before complications can be observed, can destabilise a feedback system. Furthermore, advances in the technology of both PBT and X-ray treatment may make the adjustment of the NTCP models challenging.

The applicability of NTCP models derived from X-ray data to PBT is also subject to doubt. Firstly, in a proton plan, RBE will vary with position, and proton dose will have to be converted to equivalent Xray dose before NTCP is assessed. RBE and its relationship to linear energy transfer, DNA damage complexity and tissue type are active research topics and far from fully understood with any certainty $[44,45]$.

Secondly, in PBT beam angles can be used which would not be possible with X-rays because of the exit dose. For instance, where an X-ray plan may graze an organ at risk, delivering dose to a small number of functional subunits (FSU), a PBT plan may cover a critical number of FSUs with a dramatic increase in the resulting toxicity even if the dose to each FSU is lower. The equivalent uniform dose (EUD), introduced by Niemierko [46, 47], is intended to capture these concepts rooted in the functional biology of the organ at risk. An alternative solution to this type of problem is to use a combination of NTCP models based in percolation theory as proposed by Thames et al [48] and the 
known biology of the functioning of the organs at risk. This idea is not new and is now an excellent candidate for a renewed research effort.

Models now exist which can describe in some 'bottom up' detail the processes of DNA damage and repair [49] and cell survival of complex cell populations but recently models which capture the mechanical properties of sheets of tissue have been developed [50,51]. These vertex dynamics models seem to be an excellent basis for the description of symptoms such as haemorrhagic proctitis, but so far have been applied only to embryology. Obversely, a 'top down' approach to modelling is also possible; for instance, in glioblastoma [52] and more recently in lung cancer [53]. NTCP is not necessarily the only criterion on which to select patients and a more comprehensive model has been proposed which includes elements of tumour control probability and NTCP as well as the probability of induction of secondary malignancy [54].

Finally, it should be noted that NTCP modelling is intrinsically difficult even if the outcome data are not as scattered as those in the classic paper by Emami et al [55]. In one recent study of heart toxicity in lung cancer patients, it has been shown that dose to the base of the heart is the critical factor [56]. However, in a separate study in breast cancer, the volume of the left ventricle receiving more than 5 Gy has just been shown to be a good predictor of acute coronary events [41]. Clearly, the two patient cohorts in these studies are very different in age, sex, smoking history, surgical interventions etc., but the two methodologies applied are also different and it is to be hoped that the two groups will soon exchange either data sets or analysis techniques or both. What both these studies illustrate is the care that will have to be taken in selecting truly valid endpoints for NTCP modelling.

\section{Data to Inform and Populate Models}

A key issue with modelling patient selection and demand for PBT is the current lack of evidence for clinical effectiveness [57]. There are two main contributing factors for this: while the number of 
patients treated with PBT is expanding, few centres have been open long enough to report outcomes. Additionally, the core indications for proton therapy, where the greatest benefits are expected to occur, are generally rare indications especially in paediatrics. The estimates for the UK (pop. $65 \mathrm{~m}$ ) are just under 1,500 patients per year for the defined indications list [31], of which 252 are estimated to be paediatric. In total, up to end of 2015 , there have been 131,240 reported patients treated with proton therapy around the World since 1954 [58]. Comparatively, across the 2014/2015 financial year there were 134,171 reported radiotherapy episodes in England alone [59]. Due to the increasing number of facilities, the evidence base and outcomes data are slowly expanding [57, 60-62], including some longer term follow up from the oldest centres [63-66].

The gold standard for clinical evidence is the randomised control trial (RCT) and these have to be carefully designed with respect to equipoise. Each arm of the trial needs to be equivalent (in the mind of the clinician) for the prospect of cure or improvement of quality of life

Selection of endpoints is extremely important in trial development and for proton clinical trials survival may require many years of follow-up before there is significant data. Thus trials which also look at endpoints, such as neurocognitive effects, early toxicity etc. will provide an early indication of areas where further research and investigation is required. Similarly, because of improvements in both photon and proton treatment, trials need to be developed that quantify accurately small but significant changes in the data.

While evidence level and recommendation grades have been used in medicine for a number of years $[67,68]$, a modern system to categorise evidence for therapy is being developed at the Oxford Centre for Evidence-based Medicine(OCEBM) [69]. This system is used in documents such as the Royal College of Radiologists fractionation document [20]. As Table 1and Table 2 show, for the highest grade of recommendation there has to be consistent RCT evidence and ideally it is these high levels of evidence that should be prioritised to populate the model parameters. 
Very rare tumours are especially problematic, even in large databases the evidence reporting may be skewed. For example, the US National SEER database only has a $28 \%$ coverage of the whole population [70]. Older models of radiotherapy demand used a hierarchy of epidemiological data to rank data sources, with preference being given towards national data from the relevant country of origin, however, the process of deciding these preferences was contentious $[14,71]$.

\section{Technology Creep}

Proton and X-ray technologies for radiotherapy are constantly evolving. As the cost of proton therapy is higher than radiotherapy using X-rays, any equivalent treatment through a different modality (except perhaps carbon ion treatment) that displays non-inferiority will have an instant bonus in cost-effectiveness. Recent developments include image-modulated RT, image-guided RT, stereotactic RT, volumetric modulated arc RT, 4D adaptive RT and magnetic resonance image-guided RT. These advances all attempt to improve local control, or reduce side effects, or both [72]. Imaging techniques are also improving for both diagnostics and on-board for treatment imaging, allowing an increase in targeting accuracy and precision [73].

DEM techniques can be used to explore the interaction of a new technology with a current healthcare system. Discrete events can be included to represent the additional staff, ancillary services and patient travel times. These are especially useful when combined with sub-national data to estimate the changes in demand if the PBT centres have large population catchment areas. Travel time has been investigated for X-rays but not yet for protons [74].

\section{Conclusions}

There are a number of different mathematical modelling methodologies that can be used to estimate patient numbers, demand for service and guide individual patient selection. There is no single, correct methodology and the different methods are used for different purposes. The key issue for PBT is still the dearth of direct clinical evidence and this affects the modelling. However, mathematical modelling can now be used to help to design the clinical trials that can help to provide 
the evidence. For individual patient selection, NTCP can be used to compare proton and X-ray plans, but setting the threshold for PBT will be challenging, especially initially while the technology is developing rapidly. Recently, more sophisticated modelling has been demonstrated which considers both tumour control probability and the risk of secondary cancer induction as well as normal tissue effects. Ultimately, NTCP models which capture the underlying damage to the biology of the normal tissue and not just the gross statistics will be required.

For cost-benefit analysis, QALY and Markov Chain models should be used in the planning of any new centre especially where it is intended to accept patients from a fixed indication list. But again, these models suffer from the lack of long term outcome data, clinical evidence and health utility information.

Discrete event simulation is ideally placed for service demand modelling, but to use its full potential it requires an established evidence base and granular population and incidence data. DES is potentially very flexible and is the only technique explored in this paper that can act as a general framework for cohort, costing and demand simulations.

PBT modelling over the next 5-10 years will absorb new data to create more comprehensive models that are less dependent on the specific technologies of planning and delivery, and will allow a universal approach to patient selection for PBT and support the development of smarter clinical trials.

\section{Acknowledgements}

The authors thank Prof Ran Mackay (University of Manchester and Christie Hospital) and Dr Raj Jena (University of Cambridge and Addenbrooke's Hospital) for their helpful comments in the preparation of this article. TM is partly supported by the CRUK funded ART-NET project.

\section{References}

[1] Box GEP. Science and Statistics. Journal of the American Statistical Association. 1976;71:791-9. 
[2] Aggarwal A, Sullivan R. Affordability of cancer care in the United Kingdom - Is it time to introduce user charges? Journal of Cancer Policy. 2014;2:31-9.

[3] The Christie NHS Foundation Trust. High energy PBT press release. 2015

http://www.christie.nhs.uk/about-us/news/press/nhs-patients-a-step-closer-to-having-high-energyproton-beam-therapy-in-the-uk/ [accessed 23/10/2017].

[4] Forbes. The \$150 Million Zapper. 2009

https://www.forbes.com/forbes/2009/0316/062 150mil zapper.html [accessed 23/10/2017].

[5] The National Association for Proton Therapy. Proton-Beam Therapy for Cancer Gets Renewed Attention. 2016 http://proton-therapy.org/proton-therapy-gets-renewed-attention.html [accessed 23/10/2017].

[6] Society of Radiographers. A guide to modern radiotherapy. 2013

https://www.sor.org/learning/document-library/guide-modern-radiotherapy [accessed 23/10/2017].

[7] The Christie NHS Foundation Trust. 2016 http://www.christie.nhs.uk/about-us/news/press/fourtonne-magnet-for-revolutionary-radiotherapy-machine-that-can-see-and-treat-cancer-withpinpoint-accuracy/ [accessed 24/10/2017].

[8] NewsWise. First Fully-Integrated ProteusOne Proton Cancer Treatment Center in the U.S. Hits Milestone. 2016 http://www.newswise.com/articles/first-fully-integrated-proteusone-protoncancer-treatment-center-in-the-u-s-hits-milestone [accessed 24/10/2017].

[9] Goitein M, Jermann M. The Relative Costs of Proton and X-ray Radiation Therapy. Clinical Oncology. 2003;15:s37-s50.

[10] Lundkvist J, Ekman M, Ericsson SR, Jönsson B, Glimelius B. Proton therapy of cancer: potential clinical advantages and cost-effectiveness. Acta oncologica (Stockholm, Sweden). 2005;44:850-61.

[11] Verma V, Shah C, Rwigema J-CMC, Solberg T, Zhu X, Simone CB. Cost-comparativeness of proton versus photon therapy. Chinese clinical oncology. 2016;5:56.

[12] Verma V, Mishra MV, Mehta MP. A systematic review of the cost and cost-effectiveness studies of proton radiotherapy. Cancer. 2016;122:1483-501.

[13] Widder J, van der Schaaf A, Lambin P, Marijnen C, Pignol J-P, Rasch CR, et al. The Quest for Evidence for Proton Therapy: Model-Based Approach and Precision Medicine. International Journal of Radiation Oncology*Biology*Physics. 2016;95:30-6.

[14] Delaney G, Jacob S, Featherstone C, Barton M. The role of radiotherapy in cancer treatment: estimating optimal utilization from a review of evidence-based clinical guidelines. Cancer.

2005;104:1129-37.

[15] Foroudi F, Tyldesley S, Walker H, Mackillop WJ. An evidence-based estimate of appropriate radiotherapy utilization rate for breast cancer. International journal of radiation oncology, biology, physics. 2002;53:1240-53.

[16] Williams MV, Drinkwater KJ. Radiotherapy in England in 2007: modelled demand and audited activity. Clinical oncology (Royal College of Radiologists (Great Britain)). 2009;21:575-90.

[17] Jena R, Round C, Mee T, Kirkby N, Hoskin P, Williams M. The Malthus Programme - A New Tool for Estimating Radiotherapy Demand at a Local Level. Clinical Oncology. 2012;24:1-3.

[18] Caro JJ, Möller J, Getsios D. Discrete event simulation: the preferred technique for health economic evaluations? Value in health : the journal of the International Society for Pharmacoeconomics and Outcomes Research. 2010;13:1056-60.

[19] Standfield L, Comans T, Scuffham P. Markov modeling and discrete event simulation in health care: a systematic comparison. International journal of technology assessment in health care. 2014;30:165-72.

[20] The Royal College of Radiologists. Tadiotherapy dose fractionation. Second edition. 2016 https://www.rcr.ac.uk/system/files/publication/field publication files/bfco163 dose fractionation 2nd ed march2017.pdf [accessed 06/11/2017]. 
[21] Jena R, Mee T, Kirkby NF, Williams MV. Quantifying uncertainty in radiotherapy demand at the local and national level using the Malthus model. Clinical oncology (Royal College of Radiologists (Great Britain)). 2015;27:92-8.

[22] Sanderson B, McWilliam A, Faivre-Finn C, Kirkby NF, Jena R, Mee T, et al. Using the Malthus programme to predict the recruitment of patients to MR-linac research trials in prostate and lung cancer. Radiotherapy and oncology : journal of the European Society for Therapeutic Radiology and Oncology. 2017;122:159-62.

[23] Weinstein MC, Torrance G, McGuire A. QALYs: the basics. Value in health : the journal of the International Society for Pharmacoeconomics and Outcomes Research. 2009;12 Suppl 1:s5-s9.

[24] Prieto L, Sacristán JAA. Problems and solutions in calculating quality-adjusted life years (QALYs). Health and quality of life outcomes. 2003;1:80.

[25] NICE. Methods for the development of NICE public health guidance (third edition) Incorporating health economics. 2012.

https://www.nice.org.uk/process/pmg4/chapter/incorporating-health-economics [accessed $13 / 11 / 2017]$.

[26] Owen L, Morgan A, Fischer A, Ellis S, Hoy A, Kelly MP. The cost-effectiveness of public health interventions. Journal of public health (Oxford, England). 2012;34:37-45.

[27] Smith DH, Gravelle H. The practice of discounting in economic evaluations of healthcare interventions. International journal of technology assessment in health care. 2001;17:236-43.

[28] Severens JL, Milne RJ. Discounting health outcomes in economic evaluation: the ongoing debate. Value in health : the journal of the International Society for Pharmacoeconomics and Outcomes Research. 2004;7:397-401.

[29] Amin NP, Sher DJ, Konski AA. Systematic review of the cost effectiveness of radiation therapy for prostate cancer from 2003 to 2013. Applied health economics and health policy. 2014;12:391408.

[30] Department of Health. National Proton Beam Therapy Service Development Programme Strategic Outline Case. 2012

https://www.gov.uk/government/uploads/system/uploads/attachment data/file/213044/nationalproton-beam-therapy-service-development-programme-strategic-outline-case-16102012.pdf [accessed 26/10/2017].

[31] Department of Health. National Proton Beam Therapy Service Development Programme - Value for Money Addendum to Strategic Outline Case. 2012

https://www.gov.uk/government/uploads/system/uploads/attachment data/file/213045/nationalproton-beam-therapy-service-development-programme-value-for-money-addendum.pdf [accessed 25/10/2017].

[32] Ollendorf DA, Hayes J, McMahon P, Kuba M, Pearson SD. Management Options for Low-Risk Prostate Cancer: A Report on Comparatice Effectiveness and Value. 2010 http://icer-review.org/wpcontent/uploads/2013/04/Management Options for Low-Risk Prostate Cancer Final-2.pdf [accessed 26/10/2017].

[33] Bekelman JE, Asch DA, Tochner Z, Friedberg J, Vaughn DJ, Rash E, et al. Principles and reality of proton therapy treatment allocation. International journal of radiation oncology, biology, physics. 2014;89:499-508.

[34] Paganetti H. Relative biological effectiveness (RBE) values for proton beam therapy. Variations as a function of biological endpoint, dose, and linear energy transfer. Physics in medicine and biology. 2014;59:72.

[35] Paganetti H, Niemierko A, Ancukiewicz M, Gerweck LE, Goitein M, Loeffler JS, et al. Relative biological effectiveness (RBE) values for proton beam therapy. International journal of radiation oncology, biology, physics. 2002.

[36] Mohan R, Peeler CR, Guan F, Bronk L, Cao W, Grosshans DR. Radiobiological issues in proton therapy. Acta oncologica (Stockholm, Sweden). 2017;56:1367-73. 
[37] Grau C. The model-based approach to clinical studies in particle radiotherapy - A new concept in evidence based radiation oncology? Radiotherapy and Oncology. 2013;107:265-6.

[38] Langendijk JA, Lambin P, De Ruysscher D, Widder J, Bos M, Verheij M. Selection of patients for radiotherapy with protons aiming at reduction of side effects: the model-based approach.

Radiotherapy and oncology : journal of the European Society for Therapeutic Radiology and Oncology. 2013;107:267-73.

[39] Kierkels RG, Wopken K, Visser R, Korevaar EW, van der Schaaf A, Bijl HP, et al. Multivariable normal tissue complication probability model-based treatment plan optimization for grade 2-4 dysphagia and tube feeding dependence in head and neck radiotherapy. Radiotherapy and oncology : journal of the European Society for Therapeutic Radiology and Oncology. 2016;121:374-80.

[40] Schaake W, van der Schaaf A, van Dijk LV, Bongaerts AHH, van den Bergh AC, Langendijk JA. Normal tissue complication probability (NTCP) models for late rectal bleeding, stool frequency and fecal incontinence after radiotherapy in prostate cancer patients. Radiotherapy and oncology : journal of the European Society for Therapeutic Radiology and Oncology. 2016;119:381-7.

[41] van den Bogaard VA, Ta BD, van der Schaaf A, Bouma AB, Middag AM, Bantema-Joppe EJ, et al. Validation and Modification of a Prediction Model for Acute Cardiac Events in Patients With Breast Cancer Treated With Radiotherapy Based on Three-Dimensional Dose Distributions to Cardiac Substructures. Journal of clinical oncology : official journal of the American Society of Clinical Oncology. 2017;35:1171-8.

[42] Wopken K, Bijl HP, van der Schaaf A, van der Laan HP, Chouvalova O, Steenbakkers RJ, et al. Development of a multivariable normal tissue complication probability (NTCP) model for tube feeding dependence after curative radiotherapy/chemo-radiotherapy in head and neck cancer. Radiotherapy and oncology : journal of the European Society for Therapeutic Radiology and Oncology. 2014;113:95-101.

[43] Luyben WL. Process modeling, simulation and control for chemical engineers. McGraw-Hill Higher Education; 1989.

[44] Carabe A, España S, Grassberger C, Paganetti H. Clinical consequences of relative biological effectiveness variations in proton radiotherapy of the prostate, brain and liver. Physics in medicine and biology. 2013;58:2103-17.

[45] Carabe A, Moteabbed M, Depauw N, Schuemann J, Paganetti H. Range uncertainty in proton therapy due to variable biological effectiveness. Physics in medicine and biology. 2012;57:1159-72.

[46] Niemierko A. Reporting and analyzing dose distributions: a concept of equivalent uniform dose. Medical physics. 1997;24:103-10.

[47] Niemierko A. A generalized concept of equivalent uniform dose (EUD). Medical physics. 1999;26:1100.

[48] Thames HD, Zhang M, Tucker SL, Liu HH, Dong L, Mohan R. Cluster models of dose-volume effects. International Journal of Radiation Oncology*Biology*Physics. 2004;59:1491-504.

[49] Henthorn NT, Warmenhoven JW, Sotiropoulos M, Mackay RI, Kirkby KJ, Merchant MJ.

Nanodosimetric Simulation of Direct Ion-Induced DNA Damage Using Different Chromatin Geometry Models. Radiation research. 2017;188:690-703.

[50] Fletcher AG, Osborne JM, Maini PK, Gavaghan DJ. Implementing vertex dynamics models of cell populations in biology within a consistent computational framework. Progress in biophysics and molecular biology. 2013;113:299-326.

[51] Fletcher AG, Osterfield M, Baker RE, Shvartsman SY. Vertex models of epithelial morphogenesis. Biophysical journal. 2014;106:2291-304.

[52] Barazzuol L, Burnet NG, Jena R, Jones B, Jefferies SJ, Kirkby NF. A mathematical model of brain tumour response to radiotherapy and chemotherapy considering radiobiological aspects. Journal of theoretical biology. 2010;262:553-65.

[53] Geng C, Paganetti H, Grassberger C. Prediction of Treatment Response for Combined Chemoand Radiation Therapy for Non-Small Cell Lung Cancer Patients Using a Bio-Mathematical Model. Scientific reports. 2017;7:13542. 
[54] Austin AM, Douglass MJJ, Nguyen GT, Penfold SN. A radiobiological Markov simulation tool for aiding decision making in proton therapy referral. Physica Medica. 2017;44:72-82.

[55] Emami B, Lyman J, Brown A, Coia L, Goitein M, Munzenrider JE, et al. Tolerance of normal tissue to therapeutic irradiation. International journal of radiation oncology, biology, physics. 1991;21:10922.

[56] McWilliam A, Kennedy J, Hodgson C, Vasquez Osorio E, Faivre-Finn C, van Herk M. Radiation dose to heart base linked with poorer survival in lung cancer patients. European journal of cancer (Oxford, England : 1990). 2017;85:106-13.

[57] Doyen J, Falk AT, Floquet V, Hérault J, Hannoun-Lévi J-MM. Proton beams in cancer treatments: Clinical outcomes and dosimetric comparisons with photon therapy. Cancer treatment reviews. 2016;43:104-12.

[58] Particle Therapy Co-Opoprative Group. Particle Therapy Patient Statistics (per end of 2015). 2016 https://www.ptcog.ch/archive/patient statistics/Patientstatistics-updateDec2015.pdf [accessed 23/10/2017].

[59] National Clinical Analysis and Specialised Applications Team. Radiotherapy Dataset - Annual Master RT Report 2015. 2015

http://www.natcansat.nhs.uk/dlhandler.ashx?d=pubs\&f=NATCANSAT\%20Annual\%20Master\%20RT \%20Report\%202015\%20v1.1.xls [accessed 27/10/2017].

[60] Demizu Y, Mizumoto M, Onoe T, Nakamura N, Kikuchi Y, Shibata T, et al. Proton beam therapy for bone sarcomas of the skull base and spine: A retrospective nationwide multicenter study in Japan. Cancer science. 2017;108:972-7.

[61] Takagi M, Demizu Y, Hashimoto N, Mima M, Terashima K, Fujii O, et al. Treatment outcomes of particle radiotherapy using protons or carbon ions as a single-modality therapy for adenoid cystic carcinoma of the head and neck. Radiotherapy and oncology : journal of the European Society for Therapeutic Radiology and Oncology. 2014;113:364-70.

[62] Hoppe BS, Flampouri S, Zaiden R, Slayton W, Sandler E, Ozdemir S, et al. Involved-node proton therapy in combined modality therapy for Hodgkin lymphoma: results of a phase 2 study.

International journal of radiation oncology, biology, physics. 2014;89:1053-9.

[63] Eaton BR, Esiashvili N, Kim S, Weyman EA, Thornton LT, Mazewski C, et al. Clinical Outcomes Among Children With Standard-Risk Medulloblastoma Treated With Proton and Photon Radiation Therapy: A Comparison of Disease Control and Overall Survival. International journal of radiation oncology, biology, physics. 2016;94:133-8.

[64] Ares C, Hug EB, Lomax AJ, Bolsi A, Timmermann B, Rutz HP, et al. Effectiveness and safety of spot scanning proton radiation therapy for chordomas and chondrosarcomas of the skull base: first long-term report. International journal of radiation oncology, biology, physics. 2009;75:1111-8. [65] Weber DC, Ares C, Albertini F, Frei-Welte M, Niggli FK, Schneider R, et al. Pencil Beam Scanning Proton Therapy for Pediatric Parameningeal Rhabdomyosarcomas: Clinical Outcome of Patients Treated at the Paul Scherrer Institute. Pediatric blood \& cancer. 2016;63:1731-6.

[66] Fukuda K, Okumura T, Abei M, Fukumitsu N, Ishige K, Mizumoto M, et al. Long-term outcomes of proton beam therapy in patients with previously untreated hepatocellular carcinoma. Cancer science. 2017; 108:497-503.

[67] Sackett DL. Rules of evidence and clinical recommendations on the use of antithrombotic agents. Chest. 1986;89:2s-4s.

[68] Burns PB, Rohrich RJ, Chung KC. The levels of evidence and their role in evidence-based medicine. Plastic and reconstructive surgery. 2011;128:305-10.

[69] Oxford Centre of Evidence Based Medicine. Levels of Evidence. 2009

http://www.cebm.net/oxford-centre-evidence-based-medicine-levels-evidence-march-2009/ [accessed 06/11/2017].

[70] National Cancer Institute. Overview of the SEER Program. 2017

https://seer.cancer.gov/about/overview.html [accessed 27/10/2017]. 
[71] Tyldesley S, Boyd C, Schulze K, Walker H, Mackillop WJ. Estimating the need for radiotherapy for lung cancer: an evidence-based, epidemiologic approach. International journal of radiation oncology, biology, physics. 2001;49:973-85.

[72] Høyer M, Muren LP, Glimelius B. The evolution of radiotherapy techniques in the management of prostate cancer. Acta oncologica (Stockholm, Sweden). 2015;54:821-4.

[73] Dulaney CR, Osula DO, Yang ES, Rais-Bahrami S. Prostate Radiotherapy in the Era of Advanced Imaging and Precision Medicine. Prostate cancer. 2016;2016:4897515.

[74] Gabriel G, Barton M, Delaney GP. The effect of travel distance on radiotherapy utilization in NSW and ACT. Radiotherapy and oncology : journal of the European Society for Therapeutic Radiology and Oncology. 2015;117:386-9. 
Figure 1

\begin{tabular}{|c|c|c|c|}
\hline \multirow{4}{*}{$\begin{array}{l}\text { Stage 3a } \\
10 \% \\
\text { LUCADA } \\
\text { Normalised }\end{array}$} & \multirow{2}{*}{$\begin{array}{l}\text { Surgery } 10 \% \\
\text { [Non-bulky nodal disease] }\end{array}$} & No-1 & No Radiotherapy ECRIC 71\% \\
\hline & & Positive Margin > N2 & $\begin{array}{l}\text { Radiotherapy } \\
55 / 20 \#, 60 \text { Gy/30\# if +ve margin } \\
50 / 20>\text { N2 disease Lung ART 54/30\# }\end{array}$ \\
\hline & \multirow[t]{2}{*}{ No surgery $90 \%$} & \multicolumn{2}{|c|}{$\begin{array}{l}\text { Definitive RT } 40 \% \\
\text { Concurrent chemo-RT } \\
60-66 \text { Gy in } 30-33 \#, 55 \text { Gy/20\# } \\
\text { If unable to have chemoradiotherapy consider CHART } 54 \text { Gy/36\#/12 } \\
\text { otherwise } 66 / 33 \# \text { or } 55 / 20 \# \text { Superior sulcus tumour consider preop crt } 45 \text { Gy/25\# then surgery }\end{array}$} \\
\hline & & \multicolumn{2}{|c|}{$\begin{array}{l}\text { Palliative RT } 60 \% \\
\text { High dose palliative } 36 \mathrm{~Gy} / 12 \#, 30 \mathrm{~Gy} / 10 \# \\
\text { Poor performance status focus symptoms - palliative } \\
20 \mathrm{~Gy} / 5 \#, 16 \mathrm{~Gy} / 2 \#, 10 \mathrm{~Gy} / 1 \# \text { Thoracic radiotherapy }\end{array}$} \\
\hline
\end{tabular}

Figure 1. An excerpt from the Malthus lung cancer decision tree, showing the stages of the discrete event simulation events going left to right. The key events being the determination of disease site, stage distribution, initial therapy, patient factors, evidence-based indications for radiotherapy including the number of treatment fractions. Adapted from [21]. 
Table 1

\begin{tabular}{|c|l|}
\hline Evidence Level & Data required \\
\hline $1 a$ & Systematic review (with homogeneity) of RCTs \\
\hline $1 b$ & Individual RCT (with narrow confidence intervals) \\
\hline $1 c$ & All or none study \\
\hline $2 a$ & Systematic review (with homogeneity) of cohort studies \\
\hline $2 b$ & Individual Cohort study (including low quality RCT, e.g. <80\% follow-up) \\
\hline $2 c$ & "Outcomes" research; Ecological studies \\
\hline $3 a$ & Systematic review (with homogeneity) of case-control studies \\
\hline $3 b$ & Individual Case-control study \\
\hline 4 & Case series (and poor quality cohort and case-control study \\
\hline 5 & $\begin{array}{l}\text { Expert opinion without explicit critical appraisal, or based on physiology, bench } \\
\text { research or "first principles" }\end{array}$ \\
\hline
\end{tabular}

Table 1. Levels of evidence for therapy, derived from [69] 
Table 2

\begin{tabular}{|c|l|}
\hline $\begin{array}{c}\text { Grade of } \\
\text { Recommendation }\end{array}$ & Evidence level required \\
\hline A & consistent level 1 studies \\
\hline B & consistent level 2 or 3 studies or extrapolations from level 1 studies \\
\hline C & level 4 studies or extrapolations from level 2 or 3 studies \\
\hline D & $\begin{array}{l}\text { level } 5 \text { evidence or troublingly inconsistent or inconclusive studies of any } \\
\text { level }\end{array}$ \\
\hline
\end{tabular}

Table 2. Grades of recommendation for therapy, derived from [69] 